\title{
Uso de imágenes satelitales para el reconocimiento de parapetos en el centro-oeste de Patagonia meridional
}

(7uan Dellepiane*

Recibido:

31 de marzo de 2017

Aceptado:

9 de agosto de 2017

\section{Resumen}

Las investigaciones arqueológicas llevadas a cabo en el centro-oeste de Santa Cruz (Patagonia) destacan la alta frecuencia y amplia distribución de estructuras de piedra, denominadas parapetos. Se registran principalmente en sectores de meseta, espacios que habrían sido incorporados a las dinámicas de las poblaciones que habitaron la región durante el Holoceno tardío. Este trabajo evalúa la utilidad del uso de imágenes satelitales como herramienta metodológica para facilitar el reconocimiento de parapetos en las mesetas del Strobel y Pampa del Asador- Guitarra. De esta forma, se ha utilizado el programa BingMaps, plataforma que permite la visualización de imágenes satelitales de forma libre y gratuita. Los resultados alcanzados destacan la utilidad de esta herramienta. Nuevos conjuntos de parapetos han podido ser registrados en ambas mesetas, lo que permite resaltar su potencialidad.

\section{The use of satellite images for surveying stone structures in central Western region of Southern Patagonia}

\begin{abstract}
Archaeological investigations undertaken in the central Western region of the Santa Cruz Province (Patagonia) highlight the frequency and broad distribution of stone structures known as parapetos. These are located mainly on high plateaus, areas that human populations would have incorporated into their space dynamics during Late Holocene. This paper evaluates the value of satellite images as a methodological tool that allows the remote recognition of stone structures in the Strobel Plateau and the Pampa del Asador-Guitarra Plateau. To this end, BingMaps software -a free satellite image platform- was used. The results obtained to date emphasize the effectiveness of this tool, given that new stone structures assemblages were identified.
\end{abstract}

\section{Palabras Clave}

Mesetas Holoceno tardío Parapetos Imágenes satelitales

\section{Keywords}

Plateaus Late Holocene Stone structures Satellite images 


\section{Introducción}

Las investigaciones arqueológicas llevadas a cabo en los últimos 30 años en el centrooeste de la provincia de Santa Cruz, han destacado la importancia de las mesetas para los grupos humanos que ocuparon el área durante momentos tardíos. De acuerdo con el modelo de poblamiento regional (Goñi, 2010), hacia los últimos 2500 años AP, estos espacios habrían sido incorporados a las dinámicas de las poblaciones del pasado, como parte de un conjunto de estrategias estacional/logísticas asociadas con la obtención de materia prima (Cassiodoro, 2008; Goñi, 2010), la caza estacional (Dellepiane, 2014; Rindel, 2009), la circulación de información (Goñi, 2010; Re et al., 2017) y el equipamiento del paisaje a través del uso de parapetos en puntos estratégicos (Cassiodoro, 2008; Flores Coni, 2014; Goñi, 2010; entre otros). Estos últimos, son uno de los sitios más característicos y frecuentes en este tipo de ambiente, registrándoselos en diferentes sectores de Patagonia.

La presencia de estructuras de parapetos se remite principalmente a sectores de mesetas. Estos ambientes, especialmente aquellos que se ubican por encima de los 650 m s.n.m, presentan grandes extensiones y exhiben condiciones climáticas, ecológicas, topográficas que dificultan su acceso y complejizan el desarrollo de trabajos arqueológicos sistemáticos; limitando nuestro conocimiento acerca de este particular tipo de sitio a cielo abierto. De tal manera, se presenta aquí una primera aproximación al uso de imágenes satelitales como una herramienta metodológica que facilite el reconocimiento de estructuras de piedra en estos espacios. Para tal fin, se utilizó el software BingMaps, plataforma digital que permite la visualización libre y gratuita de imágenes.

El presente trabajo se enmarca espacialmente en las mesetas del Strobel y del Guitarra, ubicadas en el centro-oeste de la provincia de Santa Cruz. Desde la década del 90', estos espacios han formado parte de numerosas investigaciones arqueológicas que han permitido registrar, aproximadamente, 425 estructuras de parapetos.

Con el fin de evaluar la utilidad del uso de imágenes satelitales como herramienta se buscó, en primera instancia, localizar la presencia de parapetos ya conocidos e identificados en campo por medio de transectas y prospecciones. En segunda instancia, se midió su potencial en sectores de la región no conocidos ni explorados hasta el momento. Finalmente, fue realizado el procedimiento inverso: las estructuras identificadas a partir de imágenes satelitales en la Pampa del Asador-meseta del Guitarra fueron posteriormente relevadas en campo a partir del trabajo de análisis realizado previamente.

\section{Imágenes satelitales}

La teledetección o cualquier otro método de percepción remota, es una herramienta técnico-metodológica para obtener información de un objeto, área o fenómeno a través del análisis de un conjunto de datos adquiridos por diversos dispositivos que no se encuentran en contacto directo con dichos objetos, áreas o fenómenos (Álvarez Larrain, 2012; Lillesand, Kiefer y Chipman, 2014; Villegas, 2009, entre otros). Se trata de sensores que detectan y registran una multiplicidad de características y propiedades de los objetos y transforman esta información en imágenes. El uso de sensores remotos es una técnica ampliamente utilizada en la arqueología argentina (Álvarez Larrain, 2012; Magnin, 2010; Matteucci y Scheinsohn, 2004, entre otros).

Dentro del campo de la teledetección, dos conceptos son de suma relevancia, dado que pueden influir en los resultados obtenidos. Por un lado, la obstrusividad es una 
característica de los objetos y establece que la probabilidad de que estos sean registrados depende de su forma, tamaño, contenido así como de las técnicas utilizadas para su descubrimiento (Villegas, 2009). Por otro lado, la visibilidad es una característica del ambiente y refiere a aquellos aspectos que puedan condicionar la observación de los objetos; tales como la cobertura vegetal, la topografía, el basamento geológico, entre otros. Por su parte, las propiedades y características de las imágenes satelitales también pueden presentar condicionantes asociados con el grado de resolución disponible, la época del año cuando fue tomada la imagen, la hora del día, etc.

En este trabajo, el registro de estructuras de parapetos a partir del análisis y visualización de imágenes satelitales, fue realizado a través del uso del software BingMaps. Este programa, creado por Microsoft y accesible desde el año 2009, permite la visualización de datos geográficos e imágenes satelitales de alta resolución (entre 10 y $5 \mathrm{~m}$ ) de manera libre y gratuita. Las imágenes son obtenidas por medio de diferentes satélites de compañías independientes. Se comercializan y son adquiridas por diversas empresas (ej. Microsoft) que lleva a cabo un procesamiento de la imagen con el objetivo de alcanzar una adecuada calibración de parámetros tales como tamaño, contraste, coloración, entre otros. Finalmente, éstas se encuentran disponibles para su visualización en diferentes plataformas digitales, tales como BingMaps, Google Earth, Here Maps, entre otros. Es importante destacar que el producto final disponible no es una imagen satelital original sino una composición producto de su procesamiento.

Su utilización es simple y similar al resto de los programas de su tipo. Cualquier sector de la tierra es factible de ser explorado y variando el grado de zoom es posible contar con mayor o menor detalle, dependiendo de la resolución disponible para cada caso. A los fines de este trabajo, es importante destacar que el programa permite obtener coordenadas geoespaciales de una localización determinada, pudiendo ubicar los sitios identificados con el software en el campo con el uso complementario de navegadores satelitales.

\section{Área de estudio}

El área de estudio considerada en este trabajo, las mesetas del Strobel y Pampa del Asador-Guitarra, se encuentran ubicadas en el centro-oeste de la provincia de Santa Cruz (Figura 1) y presentan un origen geológico vinculado con la efusión de grandes volúmenes de lava durante el Mioceno superior (Ramos, 2002). Estos espacios, se ubican dentro de la categoría de mesetas altas, con una altura promedio que oscila entre los 900 y 1400 m s.n.m.

La región ha sido definida como un ambiente semidesierto de estepa arbustiva árida, ubicado dentro del Distrito Patagónico Central de la Provincia Patagónica (Roig 1998, citado en Lancelotti, 2009; Soriano, 1956), caracterizado por un clima templadofrío árido (Paruelo, Beltrán, Jobbágy, Sala y Golluscio, 1998). El tipo de vegetación predominante es de escasa altura y constituye la expresión de la máxima aridez de las estepas patagónicas dada su fisonomía yerma y extremadamente xérica. Se caracteriza por una escasa cobertura, que no supera el 50\% y se compone principalmente de arbustos enanos en cojín alternados con una pequeña cantidad de gramíneas (León, Bran, Collantes, Paruelo y Soriano, 1998). Las especies vegetales características son colapiche (Nassauvia glomerulosa), mata negra (Verbena tridens), coirón (Festuca magellanica y Festuca pyrogea), calafate (Berberis buxifolia) (restringido a sectores de mayor protección y menor altura sobre el nivel del mar), entre otras (Roig 1998, citado en Lancelotti, 2009). En contraste, en los sectores de meseta donde se localizan vegas y mallines se desarrollan microambientes con una vegetación densa compuesta por hidrófitas (Lancelotti, 2009). 


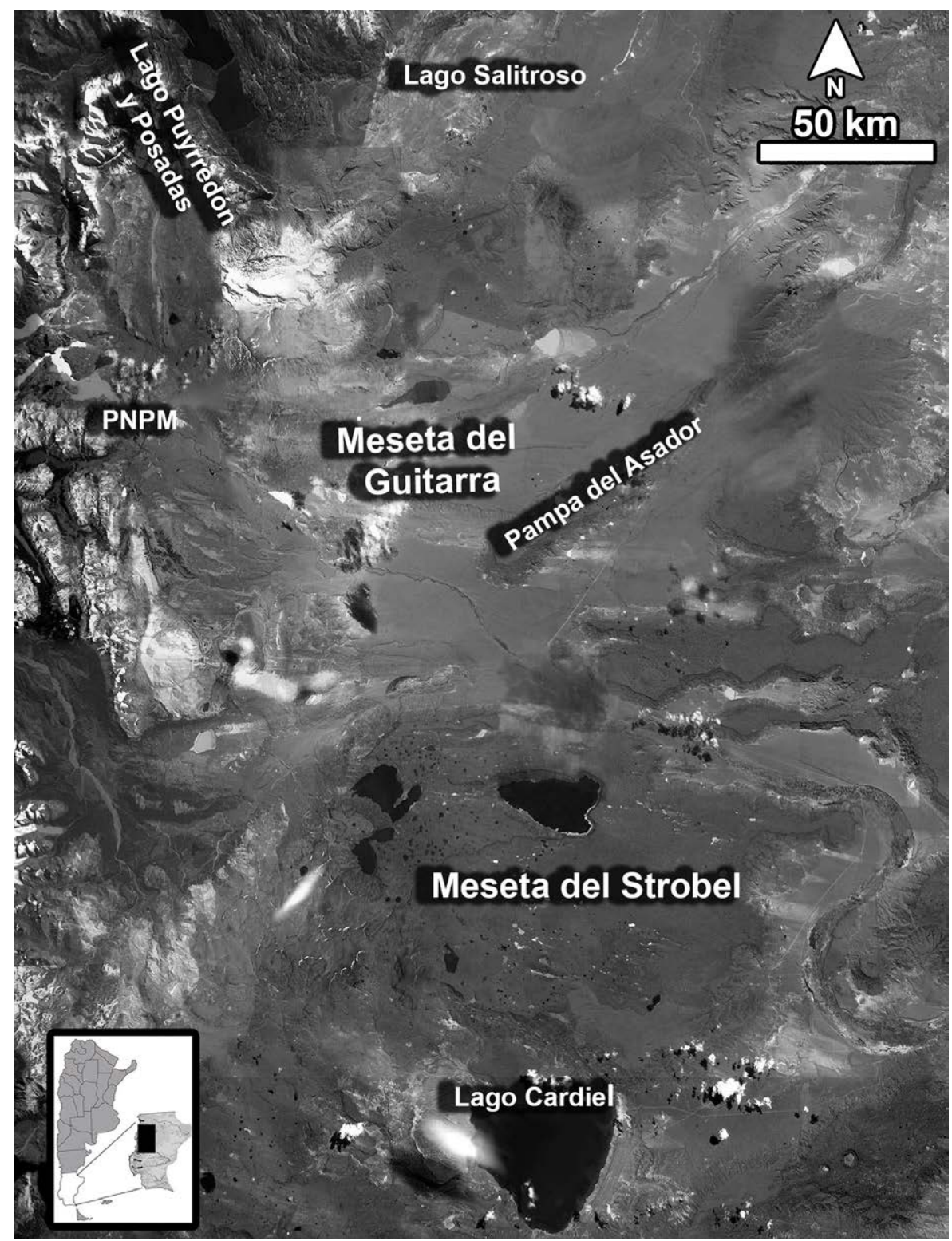

Figura 1. Región de estudio y localización de las mesetas consideradas

\section{Parapetos}

Los parapetos pueden ser definidos como estructuras de piedra, generalmente semicirculares y circulares, formados por la acumulación intencional de rocas sin argamasa (Cassiodoro, 2008) (Figura 2). Han sido reconocidos en diferentes partes del mundo y en ambientes muy variados (Binford, 1978; Frison, 1978; Lupo, 2001, entre otros). En Patagonia, su presencia es notoria, localizándose en gran parte de la región, principalmente en ambientes de mesetas (Cassiodoro, 2008; Dellepiane, 2014; Flores Coni, 2014; García y Pérez de Micou, 1979; Gradin, 1959-1960, 1971, 1976, 1996; Magnin, 2010; Prates, Serna y Mange, 2013, entre otros). Las mesetas del Strobel y del Guitarra presentan una alta frecuencia de estructuras, estableciéndose como uno de los sectores con mayor cantidad de parapetos relevados en Patagonia meridional. En cuanto a la primera han sido registrados 364 estructuras (Re et al., 2017); mientras que la segunda cuenta, hasta el presente, con 118 parapetos. 


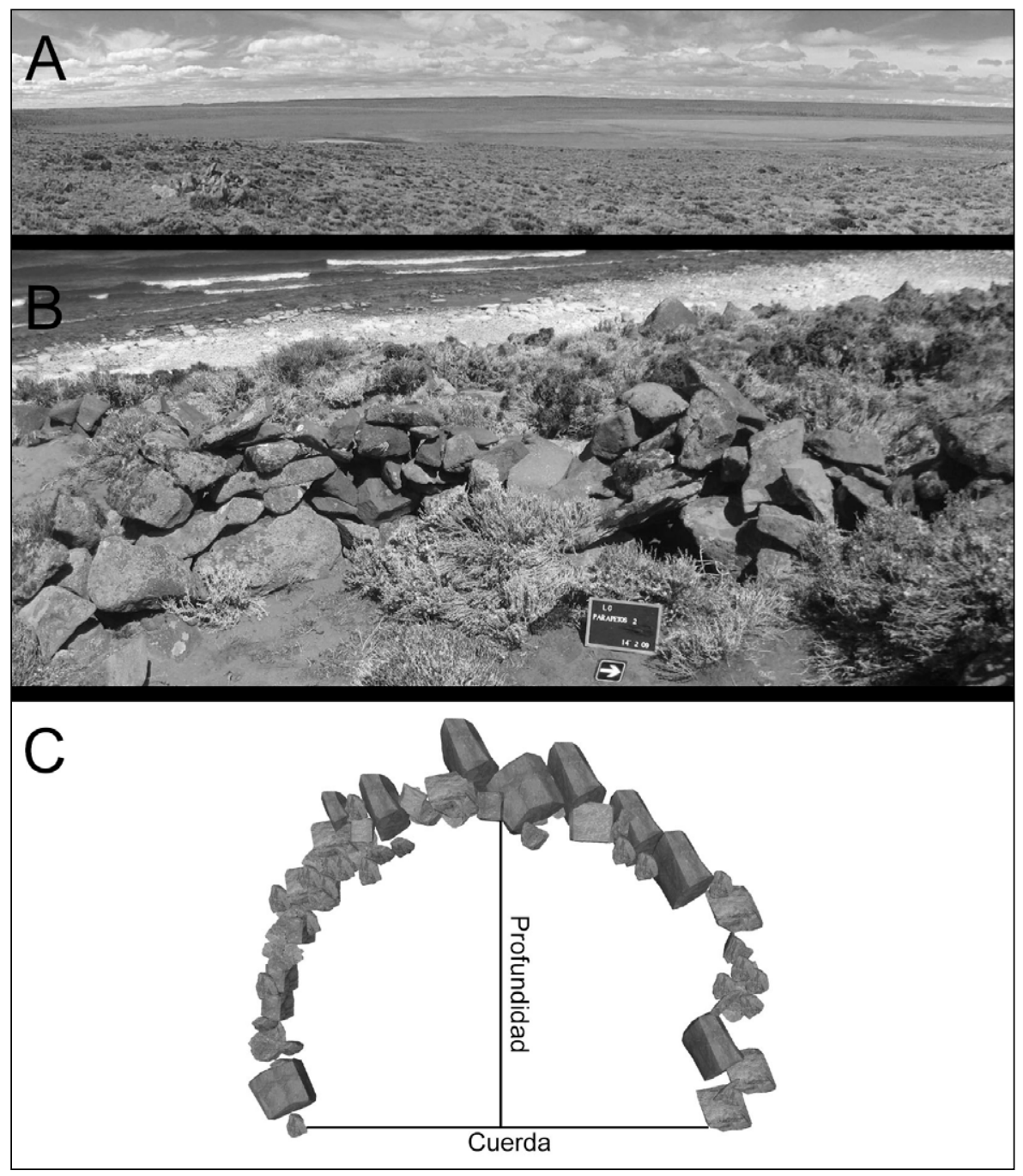

Figura 2. A) panorámica Pampa del Asador; B) parapeto 2 de GUl10; C) ejemplo grafico de una estructura de parapeto y medidas que se toman en su registro.

Los parapetos exhiben una serie de características regulares que han permitido el desarrollo de criterios que facilitan su identificación (Flores Coni, 2014). En este sentido, su orientación se encuentra generalmente en dirección oeste-este, de forma tal que el arco siempre está reparado del viento predominante del oeste (Gradín, 1959-1960). En relación con su ubicación topográfica, se localizan próximos a cuerpos de agua, sobre bordes de cañadones, en pampas altas y sobre elevaciones del terreno (Flores Coni, 2014). Por otra parte, presentan una morfología diversa, distinguiéndose estructuras en forma de semiarcos, círculos y rectos (Gradin, 1959-1960). El tamaño también puede ser otro aspecto variable, estableciéndose un rango que oscila entre 1 y $6 \mathrm{~m}$ de ancho de cuerda (Flores Coni, 2014). Finalmente, pueden presentarse aislados o en conjuntos, cuando se observa asociación directa entre estructuras y media entre ellas una distancia no mayor a $50 \mathrm{~m}$ (Flores Coni, 2014). Finalmente, en relación con su funcionalidad en el pasado, ésta ha sido vinculada con el desarrollo de actividades de caza y obtención de recursos faunísticos, así como también posibles bases de sujeción de toldos (Gradín, 1996).

Por tanto, conocer en profundidad las características generales de los parapetos es esencial a la hora de evaluar en qué medida su obstrusividad puede o no influir en su reconocimiento. En este sentido, si bien presentan diversidad en relación a su forma, 
tamaño, emplazamiento topográfico y grado de asociación, su estructuración en el ambiente es pautada y es posible reconocer una serie de recurrencias que facilitarán su discriminación en relación con otros aspectos del paisaje.

\section{Caso de estudio}

Como fuera mencionado en la introducción de este trabajo, con el fin de evaluar el potencial de las imágenes satelitales como una herramienta útil para el reconocimiento de estructuras en Patagonia, se buscó, en primer lugar, reconocer parapetos identificados en trabajos de campo previos.

De esta forma, fueron escogidos 8 sitios localizados en las diferentes mesetas consideradas (Tabla 1). El criterio de selección buscó considerar sitios intensamente relevados en los últimos años, que cuentan con una gran cantidad de estructuras y que se ubican en diferentes sectores dentro de cada una de las mesetas. Cada uno de ellos presenta morfologías circulares y en semiarco y están ubicados en diversos emplazamientos topográficos.

De acuerdo con la Tabla 1, de los ocho sitios considerados en este trabajo cinco han podido ser identificados a partir del uso de imágenes satelitales. No obstante, no todas las estructuras que los conforman han podido ser registradas. Esto puede encontrarse vinculado con una serie de factores. Por un lado, aquellos asociados con el grado de obstrusividad de cada uno de los parapetos en términos de su tamaño, altura de la pared, morfología y grado de asociación con otros. Por otro lado, también pueda deberse a la visibilidad asociada con el ambiente, es decir las características ecológicas y geomorfológicas de los sectores donde se encuentran directamente emplazadas. En este sentido, el sector este de la meseta del Strobel, presenta una mayor cobertura vegetal que el oeste de la misma, caracterizada por la presencia de densos parches circulares de arbustos de mata negra que reducen, posiblemente, el potencial de identificación de estructuras. Esto explicaría, en parte, porque no ha sido posible observar ninguna de las estructuras correspondientes al sitio K205, ubicado al este de la meseta y sí registrar otras que forman parte de sitios localizados hacia el oeste (K168 y K130) y el centro de la misma (K106 y K116). Asimismo, dado que los parapetos están construidos con la misma roca que conforma el basamento de ambas mesetas consideradas en este trabajo, aquellos localizados inmediatamente próximos a espacios con grandes afloramientos serán más difíciles de reconocer. Probablemente, este último escenario seria el caso del sitio CP2A, donde no ha sido posible observar las estructuras que lo conforman. Cada uno de estos aspectos deberá ser evaluado en profundidad a futuro con el fin de poder identificar y aislar aquellas variables que condicionan la visibilidad y el reconocimiento de parapetos.

El segundo paso en este trabajo y habiendo podido reconocer parapetos utilizando las imágenes, estuvo orientado a explorar sectores no conocidos en la meseta del Strobel y del Guitarra con el objetivo de poder identificar nuevas estructuras (Figura 3.1 y 3.3). Para ambos casos, y en función del conocimiento disponible acerca de los espacios donde generalmente se localizan (Cassiodoro 2008; Flores Coni 2014; Gradín, 19591960; entre otros), el criterio de selección de lugares se definió por su asociación y proximidad a cuerpos de agua, ya sean mallines, lagunas o cauces de mayor jerarquía.

Uno de los afluentes más importantes en la meseta del Strobel es el río Barrancoso, que discurre suroeste-noreste desde la meseta de la Muerte hasta el lago Strobel. Para el relevamiento de estructuras se seleccionó un segmento de $14 \mathrm{~km}$ de extensión con una orientación en dirección sur partiendo desde el último sitio arqueológico localizado hasta el momento (K127) en las márgenes del río. Cabe mencionar que solo fue relevado el borde inmediato de las barrancas (Figura 3.3). 


\begin{tabular}{|c|c|c|c|c|c|c|c|}
\hline Sitio & Localización & $\begin{array}{c}\text { Cantidad de } \\
\text { estructuras } \\
\text { registradas en } \\
\text { campo } \\
\end{array}$ & $\begin{array}{c}\text { Cantidad de } \\
\text { estructuras } \\
\text { identificadas en las } \\
\text { imágenes satelitales }\end{array}$ & Unidad topográfica & $\begin{array}{l}\text { Cobertura } \\
\text { vegetal }\end{array}$ & Morfología & $\begin{array}{c}\text { Rango de } \\
\text { tamaño (mt) }\end{array}$ \\
\hline GUl10 & $\begin{array}{c}\text { Pampa del } \\
\text { Asador-meseta } \\
\text { del Guitarra }\end{array}$ & 11 & 2 & $\begin{array}{c}\text { Sobreelevación } \\
\text { próximo a costa del } \\
\text { lago Guitarra }\end{array}$ & Alta & Arco-Circular & $2.1-6.3$ \\
\hline $\mathrm{CP} 6$ & $\begin{array}{c}\text { Pampa del } \\
\text { Asador-meseta } \\
\text { del Guitarra }\end{array}$ & 13 & o & $\begin{array}{c}\text { Pampa próxima a } \\
\text { lagunas }\end{array}$ & Alta & Arco-Circular & $1,6-5,6$ \\
\hline $\mathrm{CP}_{2} \mathrm{~A}$ & $\begin{array}{c}\text { Pampa del } \\
\text { Asador-meseta } \\
\text { del Guitarra }\end{array}$ & 8 & $\mathrm{o}$ & $\begin{array}{c}\text { Sobre elevación/ } \\
\text { afloramiento próxima } \\
\text { a lagunas }\end{array}$ & Baja & Arco & $2.1-5.9$ \\
\hline $\mathrm{K}_{130}$ & $\begin{array}{c}\text { meseta del } \\
\text { Strobel }\end{array}$ & 9 & 3 & Borde de cañadón & Baja & $\begin{array}{c}\text { Arco-Circular } \\
\text { y Recto }\end{array}$ & $2.2-4.3$ \\
\hline K116 & $\begin{array}{c}\text { meseta del } \\
\text { Strobel }\end{array}$ & 55 & 5 & Pampa & Baja & \begin{tabular}{|c|}
$\begin{array}{c}\text { Arco-Circular } \\
\text { y Recto }\end{array}$ \\
\end{tabular} & $1.4-9$ \\
\hline K106 & $\begin{array}{l}\text { meseta del } \\
\text { Strobel }\end{array}$ & 6 & 3 & $\begin{array}{c}\text { Pampa próxima a } \\
\text { lagunas }\end{array}$ & Baja & Arco-Circular & $1.7-4$ \\
\hline K168 & $\begin{array}{c}\text { meseta del } \\
\text { Strobel }\end{array}$ & 10 & 5 & $\begin{array}{c}\text { Pampa próxima a } \\
\text { lagunas }\end{array}$ & Baja & Arco-Recto & $1.6-3.5$ \\
\hline K205 & $\begin{array}{c}\text { meseta del } \\
\text { Strobel }\end{array}$ & 10 & o & Pampa & Alta & Arco-Circular & $2.3-8.2$ \\
\hline
\end{tabular}

Tabla 1. Sitios localizados.

Los resultados obtenidos han permitido reconocer 62 nuevas estructuras de parapetos localizadas en su totalidad en la barda este del río Barrancoso. Las mismas se encuentran agrupadas en diversos sectores a lo largo del segmento relevado (Figura 3.3) y asociadas, generalmente, con sectores de menor pendiente que permiten el descenso de animales (guanacos) al río desde la meseta, escenario apropiado para el desarrollo de diversas estrategias de caza. Los parapetos se encuentran principalmente asociados en concentraciones de 4 a 6 estructuras, reconociéndose puntos con mayores agrupamientos que alcanzan una cantidad total de 11. No obstante, también fueron identificados parapetos aislados. En relación a su morfología, se evidenciaron tanto circulares como en semiarco. A la luz de lo mencionado anteriormente, resulta esperable que la cantidad de estructuras aumente considerablemente cuando este sector sea prospectado en campo. En la Figura 3.4 se presenta, a modo de ejemplo, una de las concentraciones de parapetos registradas en las márgenes del Rio Barrancoso, reconociéndose una importante cantidad de estructuras, semicirculares principalmente.

Para la Pampa del Asador-meseta del Guitarra, se seleccionó un área ubicada en el extremo oeste de la misma, próxima a la meseta del Águila (Cassiodoro, 2008). Se trata de un borde de meseta en asociación directa con un gran mallín que desemboca en el lago Guitarra (Figura 3.1). La superficie observada fue de aproximadamente $4 \mathrm{~km}$. El análisis realizado arrojó como resultado la presencia de 17 nuevos parapetos. Pudieron discriminarse tres concentraciones, una conformada por 8 estructuras (Figura 3.2), otra por 5 y la última por 3. De acuerdo con las imágenes satelitales, todas las estructuras presentan forma de semiarco. Solo fue registrado un parapeto aislado.

Con el objetivo de contrastar si las nuevas estructuras del Guitarra visualizadas en las imágenes eran efectivamente parapetos, en los trabajos de campo del 2016 se accedió al conjunto de ocho estructuras (Figura 3.2). Una de las principales diferencias registradas en relación con la caracterización realizada a partir de las imágenes satelitales refiere a la morfología de las estructuras. En este sentido, pudo constatarse en campo que no todas ellas presentan forma de semiarco, reconociéndose cinco parapetos circulares. Asimismo, sumado a los parapetos registrados, se evidenció uno más de pequeñas dimensiones que no había sido observado en las imágenes. En este último caso, su baja obstrusividad en relación con su tamaño puede establecerse como la principal causa asociada a su no reconocimiento. 


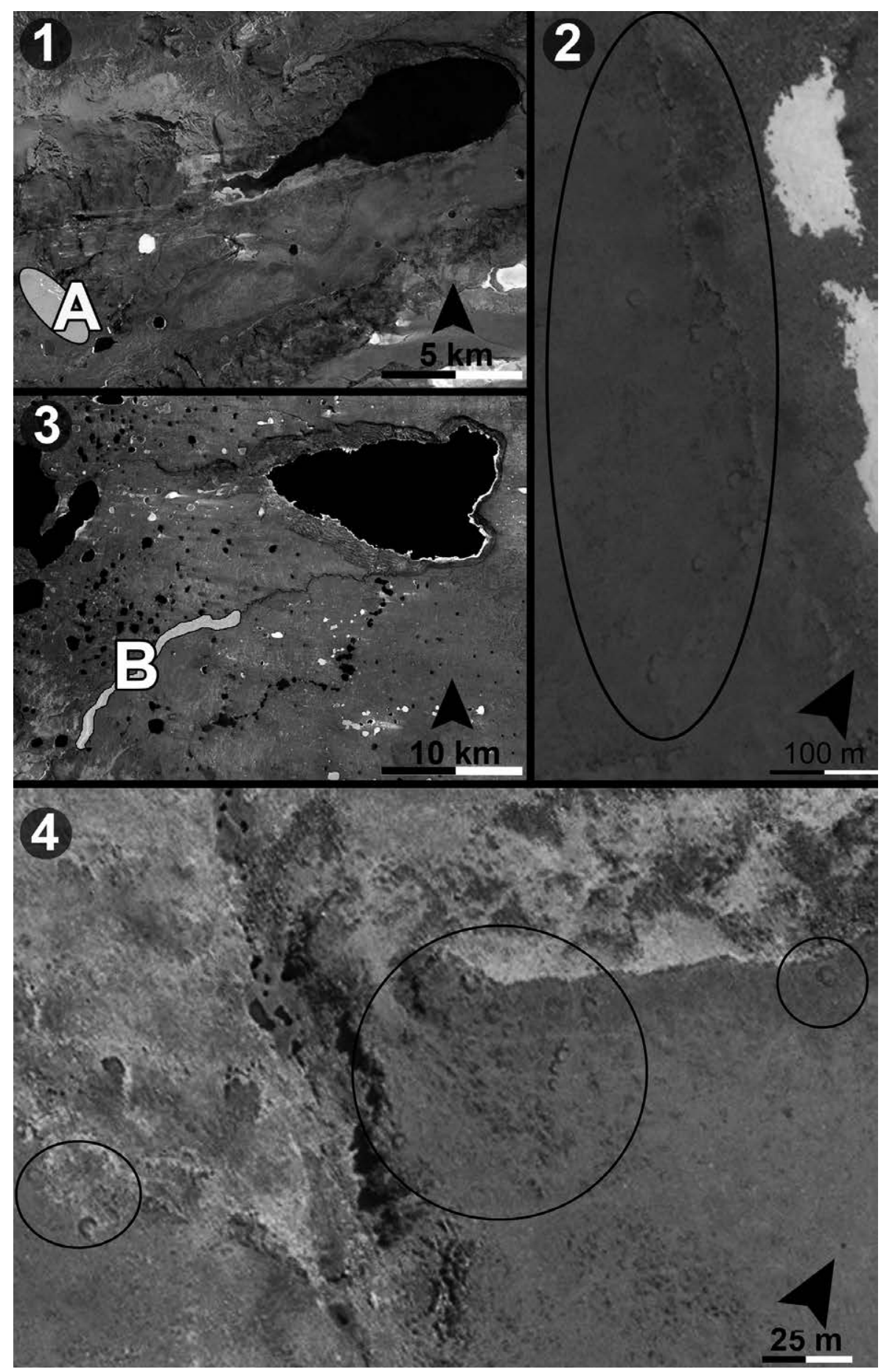

Figura 3. Ubicación geográfica de los sectores de muestreo. 1) meseta del Guitarra y sector de muestreo A; 2) ejemplo: Concentración de 8 estructuras registradas en la meseta del Guitarra a través de imágenes satelitales; 3) meseta del Strobel y sector de muestreo B; 4) ejemplo: concentración de estructuras registradas en la meseta del Strobel a través de imágenes satelitales.

\section{Conclusiones}

El uso de la teledetección resulta extremadamente útil para el desarrollo de investigaciones arqueológicas en Patagonia. En este sentido, los resultados obtenidos en este trabajo demuestran la potencialidad de las imágenes satelitales de alta resolución 
como una herramienta metodológica relevante para el reconocimiento de parapetos en el área, habiendo permitido aumentar considerablemente la cantidad de estructuras conocidas. Específicamente, ha sido posible detectar 72 nuevos parapetos que equivalen al $17,2 \%$ del total registrado hasta el momento.

Sumado a la detección de nuevos sitios, el análisis de imágenes satelitales de buena resolución brinda una excelente perspectiva general del paisaje donde estos se localizan. Ofrece, entonces, no solo una visualización holística de la disposición, distribución y grado de asociación entre estructuras, lo cual resulta muy dificultoso en el campo, sino que también permite evaluar la relación que presentan con el contexto ecológico inmediato (proximidad a fuentes de agua, topografía, rasgos geomorfológicos del paisaje, entre otros). La posibilidad de combinar estos datos junto con la información arqueológica obtenida por medio de excavación y prospecciones, permitirá avanzar en el estudio de problemáticas asociadas con la obtención de recursos faunísticos, las estrategias de caza y el uso y ocupación diferencial de los espacios.

Como ha sido mencionado en la introducción de este trabajo, los parapetos se localizan principalmente en ambientes de mesetas. Éstos son sectores de grandes dimensiones y de difícil acceso para cualquier medio de transporte exceptuando el caballo y/o largas caminatas. El uso de imágenes satelitales es una herramienta de enorme utilidad, no solo para el descubrimiento de nuevos sitios sino también para la planificación y diseño de los trabajos de campo. Asimismo, atendiendo que el 63\% de la superficie de la provincia de Santa Cruz está representada por mesetas; se considera que los resultados alcanzados en este trabajo podrán ser de utilidad para las investigaciones llevadas a cabo en la región.

\section{Agradecimientos}

A Gisela Cassiodoro, Rafael Goñi, Josefina Flores Coni, Fabián de Haro, Francisco Guichón y Agustín Agnolin por la lectura, observaciones y comentarios realizados al manuscrito. A los evaluadores de este trabajo que gracias a sus sugerencias y comentarios mejoraron el presente trabajo. A las comunidades de Perito Moreno y Gobernador Gregores por toda su hospitalidad y su invaluable apoyo. Las investigaciones fueron financiadas por los proyectos PICT 2012-1352, PICT 2013-1965, UBACyT 20020130100293BA, PIP-0122, PIP 2013-2015 11220120100406 CO y el Instituto Nacional de Antropología y Pensamiento Latinoamericano (INAPL), Ministerio de Cultura de la Nación. 


\section{Q Referencias citadas}

" Alvarez Larrain, A. (2012). Sudeste del valle de Yocavil: Teledetección y paisajes arqueológicos. En N. Kuperszmit, L. Mucciolo, T. Lagos Mármol y M. Sacchi (Eds.), Entre Pasados y Presentes III. Estudios contemporáneos en Ciencias Antropológicas (pp. 10161036). Buenos Aires: Editorial Mnemosyne.

» Binford, L. (1978). Dimensional analysis of behavior and site structure: learning from an Eskimo hunting stand. American Antiquity, 43(3), 330-361.

"Cassiodoro, G. (2008). Movilidad y uso del espacio de cazadores recolectores del Holoceno tardío: estudio de la variabilidad del registro tecnológico en distintos ambientes del noroeste de la provincia de Santa Cruz. (Tesis Doctoral inédita), Universidad de Buenos Aires, Argentina.

"Dellepiane, J. (2014). Zooarqueología de espacios mesetarios. Patrones de subsistencia y obtención de recursos en el centro-oeste de Santa Cruz durante el Holoceno tardío. (Tesis de Licenciatura inédita), Universidad Nacional del Centro de la Provincia de Buenos Aires, Argentina.

"Flores Coni, J. (2014). Análisis de la variabilidad de parapetos en la meseta del Strobel (Santa Cruz). Relaciones de la Sociedad Argentina de Antropología, XXXIX (2), 551-557.

»Frison, G. (1978). Prehistoric Hunters of the High Plains. Nueva York: Academic Press.

" García, L. y Pérez de Micou, C. (1979). Aproximación a un análisis funcional de parapetos pertenecientes al complejo patagoniense en la meseta de Somuncurá, provincia de Río Negro. Sapiens, 4, 139-144.

"Goñi, R. (2010). Cambio climático y poblamiento humano durante el Holoceno tardío en Patagonia meridional Una perspectiva arqueológica. (Tesis Doctoral inédita), Universidad de Buenos Aires, Argentina.

" Gradín, C. (1959-1960). Petroglifos de la meseta del lago Strobel (prov. de Santa Cruz, Argentina). Acta Praehistorica, 3-4, 123-143.

» Gradín, C. (1971). Parapetos habitacionales en la meseta de Somuncurá, provincia de Río Negro. Relaciones de la Sociedad Argentina de Antropología, 5(2), 171-185.

»Gradín, C. (1976). Parapetos de piedra y grabados rupestres de la meseta del lago Buenos Aires. Actas y Memorias del IV Congreso Nacional de Arqueología Argentina. Revista del Museo Historia Natural de San Rafael, 3(1-4), 315-337.

"Gradín, C. (1996). Grabados y parapetos de la zona sur de la meseta del Lago Buenos Aires (prov. de Santa Cruz). En J. Gómez Otero (Ed.), Arqueología. Sólo Patagonia (pp. 173-184). Puerto Madryn: CENPAT, CONICET.

"Lancelotti, J. (2009). Caracterización limnológica de lagunas de la Provincia de Santa Cruzy efectos de la introducción de Trucha Arco iris (Oncorhynchus mykiss) sobre las comunidades receptoras. (Tesis Doctoral inédita), Universidad Nacional del Comahue, Argentina.

» León, R., Bran, D., Collantes, M., Paruelo, J. M. y Soriano, A. (1998). Grandes unidades de vegetación de la Patagonia extra andina. Ecología Austral, 8, 125-144.

"Lillesand, T., Kiefer, R. W. y Chipman, J. (2014). Remote sensing and image interpretation. Nueva Jersey: John Wiley \& Sons.

"Lupo, K. (2001). On the archaeological resolution of body part transport patterns: An ethnoarchaeological example from East African hunter-gatherers. Journal of Anthropological Archaeology, 20, 361-378. 
" Magnin, L. (2010). Distribuciones arqueológicas en la Meseta Central de Santa Cruz. Implicancias para los estudios de uso del espacio y movilidad de sociedades cazadorasrecolectoras. (Tesis Doctoral inédita), Universidad Nacional de La Plata, Argentina.

» Mateucci, S. D. y Scheinsohn, V. (2004). Procesamiento de imágenes, SIG y modelos ecológicos aplicados a la arqueología. Revista GeoFocus, 4, 93-109.

» Paruelo, J., Beltrán, A., Jobbágy, E., Sala, O. y Golluscio, R. (1998). The climate of Patagonia: general patterns and controls on biotic processes. Ecología Austral, 8, 85-101.

» Prates, L., Serna, A. y Mange, E. (2013). Recintos de Aguada. Estructuras de piedra prehispánicas en el este de Norpatagonia (Dpto. de Valcheta), Trabajo presentado en el XVIII Congreso Nacional de Arqueología Argentina, La Rioja, Argentina.

» Ramos, V. (2002). El magnetismo neógeno de la cordillera patagónica. En M. Haller (Ed.), Geología y Recursos Naturales de Santa Cruz (pp. 187-199). Buenos Aires: Asociación Geológica Argentina.

»Re, A., Goñi, R., Flores Coni, J., Guichón, F., Dellepiane, J. y Umaño, M. (2017). Arqueología de la meseta del Strobel: 15 años después. Relaciones de la Sociedad Argentina de Antropología, XLII(1), 133-158.

»Rindel, D. (2009). Arqueología de momentos tardíos en el noroeste de la Provincia de Santa Cruz (Argentina): una perspectiva faunística. (Tesis Doctoral inédita), Universidad de Buenos Aires, Argentina.

»Soriano, A. (1956). Los distritos florísticos de la Provincia Patagónica. Revista de Investigaciones Agrícolas, 10(4), 23-347.

»Villegas, M. P. (2009). Un ojo en el Cielo. El valle Calchaquí medio visto desde la fotografía aérea. Arqueología, 15, 109-126. 